\title{
Terminología de la función del tracto urinario inferior
}

\author{
E. Martínez Agulló \\ Servicio de Urología. Hospital Universitario La Fe. Valencia.
}

Actas Urol Esp 2005; 29 (1): 5-7

$\mathrm{L}$ a comunicación entre investigadores es esencial para el intercambio de conocimientos. Disponer de un lenguaje común evita malos entendidos. Sin embargo, para que el lenguaje sea efectivo, no es suficiente utilizar las mismas palabras, escribir los mismos grafismos o pronunciar los mismos sonidos, es necesario que el significado de las palabras sea el mismo para todos aquellos que las usan. Términos y conceptos definen y acotan una ciencia. No es infrecuente en nuestro lenguaje científico el empleo de diferentes términos para idénticos conceptos y viceversa. Por lo tanto, es necesario tratarlos con el respeto y cariño que se merecen. Sin ellos la ciencia es un caos.

En la década de los setenta, se produjo un gran avance en el área de los conocimientos neurofisiológicos y fisiopatológicos del tracto urinario inferior (TUI). Junto al desarrollo tecnológico y la introducción en la práctica clínica de la urodinámica, generaron el nacimiento de un gran número de nuevos conceptos. Hubo que definirlos y establecer términos de forma rápida. Esto produjo un solapamiento de antiguos y nuevos conceptos causando imprecisión y confusión en la comunicación científica. Términos como vejiga neurógena automática, vejiga neurógena supranuclear, vejiga neurógena suprasacra, vejiga neurógena espástica, vejiga neurógena de neurona motora superior coexistían para etiquetar lo que hoy llamamos hiperactividad del detrusor de causa neurológica. Aún en la actualidad, nos sorprende ver como en los foros científicos de comunicación y en publicaciones, reaparecen términos que se abandonaron hace muchos años por inadecuados y obsoletos. Términos como vejiga paralítica, vejiga espástica, vejiga autónoma, vejiga de neurona motora inferior y un largo etcétera están hoy superados.
Planteada esta problemática en nuestra especialidad, era preciso llegar a un consenso en terminología que hiciese posible la comunicación en los foros científicos para facilitar la comprensión y comparación de resultados entre investigadores. De esta forma, a primeros de los años setenta, la Sociedad Internacional de Continencia (ICS) creó un subcomité terminológico con el objetivo de definir los nuevos conceptos sobre función del TUI y su metodología de estudio. A través de un trabajo metódico y continuo, este subcomité ha realizado un gran esfuerzo, como lo demuestran los diferentes informes de estandarización terminológica publicados ${ }^{1-3}$.

Los informes de estandarización terminológica de la ICS han seguido una evolución siempre paralela a los nuevos conocimientos científicos y técnicos y han servido de referente a la literatura científica. Sin embargo, aunque aceptados internacionalmente en lengua inglesa, plantean algunas dificultades en su traducción literal al Español. Los urólogos españoles han percibido estas dificultades desde principios de los años ochenta. Así, en el libro sobre Vejiga Neurógena: "Neurourología y urodinámica“ (Valencia 1983) se introdujeron las aportaciones de los tres primeros trabajos de la ICS firmados por C. P. Bates y cols. $1976^{4}$, en 1989 se publicaba en Urodinámica Aplicada el trabajo de la $\mathrm{ICS}^{5}$, en 1990 fue capítulo del libro "Incontinencia Urinaria, Conceptos Actuales"6 y en 1991 lo fue del Libro Blanco sobre Incontinencia Urinaria del Ministerio de Sanidad y Consumo ${ }^{7}$. Por otra parte, la Sociedad Iberoamericana de Neurourología y Uroginecología estableció, desde su primera reunión en Barcelona en 1987, la necesidad de poner orden terminológico en lengua española siguiendo el ejemplo de la ICS. Así, desde entonces hasta la actualidad (La Toja 2004), en todos sus congresos se han reali- 
zado seminarios de conceptos y terminología revisando los informes de la ICS. Por último, en el ámbito de la Sociedad Española de Urología y, dentro de ella, el grupo de Urodinámica y el Comité de Salud Vesical, tienen gran interés en este tema. Puesto que es vital y primordial para la misma, ya que conceptos y términos son su herramienta de trabajo.

Por todo lo anterior, nos pareció que era hora de realizar un nuevo trabajo de revisión y traducción del último informe sobre estandarización de la terminología de la función del TUI de la ICS ${ }^{8}$. De esta forma, hace dos años se inició un trabajo laborioso y minucioso de traducción consensuada y homologación para adaptarlo a nuestra lengua.

No es fácil llegar a un consenso absoluto en el tema que nos concierne. Así, se realizó una primera traducción español del informe publicado en el 2002 en la revista "Neurología y Urodinámica por el subcomité de la ICS. De esta forma, se dispuso de un documento base sobre el que trabajar. Esta aproximación, se publicó en la revista Urodinámica Aplicada y se invitó a sus suscriptores a dar su opinión respecto a los cambios y novedades que aportaba el trabajo ${ }^{9,10}$. Posteriormente, en Octubre del 2003, se realizaron dos seminarios paralelos en Valencia. En ellos participaron veintinueve urólogos $\mathrm{y}$, aunque se fue perfilando el documento final, aún no se logró una revisión completa del tema. Por ello, aprovechando el Congreso de la Sociedad Iberoamericana de Neurourología y Uroginecología (SINUG) de La Toja 2004, se continuó con la labor de consenso para lograr un documento final. Se realizaron seis seminarios en tres días llegando a un documento final, el cual se publica en este número de Actas Urológicas Españolas. Aunque aún existen algunas opiniones divergentes y quedan puntos a debatir es preciso publicar el trabajo realizado, de lo contrario estaríamos retrasando la comunicación a los urólogos de las novedades y cambios impuestos por la evolución científica.

Quiero dejar constancia de los urólogos que han participado en la elaboración de esta propuesta. La traducción del documento base publicado en Urodinámica Aplicada fue realizada por Roberto Martínez García, José Luis Ruiz-Cerdá,
Salvador Arlandis Guzmán, Juan Conejero Sugrañes y Eduardo Martínez Agulló. El debate dentro de la citada revista fue conducido por su director Luis Prieto. En el participó Omar Jara Michael con su autorizada opinión. Los seminarios del curso celebrado en Valencia en el 2003 fueron dirigidos por los profesores Ignacio Ponce de León y Luis Resel Estévez, moderados por David Castro Díaz y Pedro Arañó Bertrán, siendo secretarios José Antonio Díaz Cabrera y Luis Prieto Chaparro. Participaron en estos seminarios: Pedro Blasco Hernández, Francisco Delgado Oliva, Susana de la Rosa Khermann, Ángel Elizalde Amatria, Carlos Errando Smet, Edilberto Fernández Fernández, Agustín Franco de Castro, Maria Justa García Matres, Eugenia García Sastre, Luis Gómez Pérez, Fernando González Chamorro, Miguel Ángel Jiménez Cidre, J. Fernando Jiménez Cruz, Antonio Leal López, Eduardo Leal Dueñas, Antonio Marqués Queimadelos, Carlos Miguélez Lago, Valentín Orejas López, José María Pena Outeriño, Lorenzo Perales Cabanas, Pablo Pomar Moya-Prats, Manuel Ravina Pisaca, Carlos Ramos Roncero, Manuel Rapariz González, Carlos Rioja Sanz, Jesús Romero Maroto, Jesús Salinas Casado, Carmen Zubiaur Liban. El trabajo resultante fue consensuado por Carlos Rioja Sanz y se reabrió este año en la Toja durante el octavo congreso de la SINUG. En sus seminarios, además de los ya mencionados, participaron Miguel Tallado Buñuel, Omar Jara Michael y Danilo Jara.

El debate sigue abierto a la opinión de todos los urólogos a quien, desde esta editorial, invito a participar para lograr el objetivo principal de conseguir una comunicación correcta y fluida en nuestra especialidad. Por último quisiera realizar una precisión. El trabajo realizado por el subcomité de expertos de la ICS es la mejor pauta a seguir y, desde aquí, es obligado reconocer la valía de lo realizado. Sin embargo, debemos también hacer una serie de consideraciones precisas, que tienen una pura connotación de advertencia y no de crítica. Algunos de los conceptos y términos acuñados por el comité de expertos están constantemente cambiando. Sabemos que ciencia y lengua son evolutivas y vivas. Sin embargo, los cambios se han producido sobre conceptos jóvenes en años. Estas mutaciones rápidas 
pueden generar desconcierto en los foros de comunicación. Por ello, sería aconsejable pedir un periodo de vigencia prudente para cada una de las revisiones que se realizan del informe de estandarización terminológica. Puesto que, conceptos como nicturia, urgencia motora, urgencia sensorial o hiperreflexia, que en su día nos parecieron acertados y claros, hoy han sido cambiados $\mathrm{y}$, por lo tanto, su uso no se considera correcto. Los cambios deberían instaurarse dentro de la tolerancia que es necesaria en cualquier tránsito. Advirtiéndose siempre de la realidad de estar fuera de las reglas consensuadas.

\section{REFERENCIAS}

1. Bates CP, Glen E, Griffiths D, Melchior H, Rowan D, Zinder N, Hold T. First report on the standarization of terminology of lower urinary tract funtion. $\mathrm{Br} \mathrm{J}$ Urol 1976;48:39.

2. Bates CP, Glen E, Griffiths D, Melchior H, Rowan D, Zinder N, and Hold T: "Second report on the standarization of terminology of lower urinary tract funtion”. Br. J. Urol. 49: 207. 1977.

3. Bates CP, Bradley W.E, Glen E, Griffiths D, Melchior H, Rowan D, Sterling A, and Hold, T: "Third report on the standarization of terminology of lower urinary tract funtion”. Br. J. Urol. 49: 207. 1977.

4. Martínez Agulló, E.: “Cistomanometría. En Vejiga Neurógena: Neurourología y Urodinámica. Ed. Graficuatre. Valencia, 1983: 103-152.

5. Castro D, Martínez Agulló E, Conejero J. Propuesta de terminología de la función del tracto urinario y vaciado vesical; fase de llenado y vaciado vesical en Urodinámica Aplicada Valencia 1989 (1): 39-44.

6. Castro D, Martínez Agulló E, Conejero J. Propuesta de terminología de la función del tracto urinario. En Incontinencia Urinaria. Conceptos Actuales. Madrid 1990: 737-754.

7. Conejero J, Martínez Agulló E, Garriga J. Definición y conceptos en Terminología. En Libro Blanco de la Incontinencia Urinaria de España. Ministerio de Sanidad y Consumo. Madrid 1991.

8. Abrams P and cols. The standarization of terminology in lower urinary tract. Function: Report from the standarization sub-comitte of the International Continence Society. Neurourology and Urodinamics 2002; 21:167-178.

9. Martínez García R, Ruiz-Cerdá JL, Arlandis Guzman S, Conejero Sugrañes J, Martínez Agulló E. Terminología y Conceptos de la función del Tracto Urinario Inferior. En Urodinámica Aplicada 2002 15(4):281-298.

10. Terminología en Urodinámica: Urodinámica Aplicada. 2003: 16(2):63-65. 